Running head: SPONTANEOUS USE OF MENTALISTIC LANGUAGE IN AUTISM

\title{
Knowing Me, Knowing You: Spontaneous Use of Mentalistic Language for Self and Other in Autism
}

\author{
Alexandra Zinck* \\ Clinic for Child and Adolescent Psychiatry, Psychotherapy and Psychosomatic Medicine, \\ University Hospital Leipzig, Germany \\ Uta Frith \\ Institute of Cognitive Neuroscience, University College London, United Kingdom \\ Peter Schönknecht \\ Department of Psychiatry and Psychotherapy, University Hospital Leipzig, Germany \\ Sarah White \\ Institute of Cognitive Neuroscience, University College London, United Kingdom
}

Author Note

Alexandra Zinck, Department of Psychiatry and Psychotherapy, University Hospital Leipzig, Germany, alexandra.zinck@medizin.uni-leipzig.de; Uta Frith, Institute of Cognitive Neuroscience, University College London, United Kingdom, u.frith@ucl.ac.uk; Peter Schönknecht; Department of Psychiatry and Psychotherapy, University Hospital Leipzig, Germany, Peter.Schoenknecht@medizin.uni-leipzig.de; Sarah White, Institute of Cognitive Neuroscience, University College London, United Kingdom, s.white@ucl.ac.uk.

Alexandra Zinck is now at the Clinic for Child and Adolescent Psychiatry, Psychotherapy and Psychosomatic Medicine, University Hospital Leipzig. 
*Correspondence concerning this article should be addressed to Alexandra Zinck, Clinic for Child and Adolescent Psychiatry, Psychotherapy and Psychosomatic Medicine, University Hospital Leipzig: alexandra.zinck@medizin.uni-leipzig.de, Telephone: 0049-341 97 24002, Fax: 0049-341-9724019.

\section{Authors' contributions}

AZ and UF conceived and designed the study. Data was collected and transcribed by AZ and SW. AZ, UF, SW and PS analysed and interpreted the data. AZ and SW wrote the manuscript. All authors read and approved the final manuscript. 


\title{
Knowing Me, Knowing You: Spontaneous Use of Mentalistic Language for Self and Other in Autism
}

\begin{abstract}
Recent studies on mentalizing have shown that autistic individuals who pass explicit mentalizing tasks may still have difficulties with implicit mentalizing tasks. This study explores implicit mentalizing by examining spontaneous speech that is likely to contain mentalistic expressions. The spontaneous production of meta-statements provides a clear measure for implicit mentalizing that is unlikely to be learned through experience.

We examined the self- and other-descriptions of highly verbally-able autistic and non-autistic adults in terms of their spontaneous use of mentalistic language and meta-representational utterances through quantitative and qualitative analysis. We devised a hierarchical coding system that allowed us to study the types of statements produced in comparable conditions for the self and for a familiar other.

The descriptions of autistic participants revealed less mentalistic content relating to psychological traits and meta-statements. References to physical traits were similar between groups. Within each group, participants produced a similar pattern of types of mental utterance across 'self' and 'other' conditions.

This suggests that autistic individuals show a unique pattern of mental-state-representation for both self and other. Meta-statements add a degree of complexity to self- and other- descriptions and to the understanding of mental states; their reduction in autism provides evidence for implicit mentalizing difficulties.
\end{abstract}




\section{Keywords}

Autism Spectrum Disorder (ASD), explicit mentalizing, implicit mentalizing, theory of own and other minds, language, meta-cognition

\section{Lay abstract}

Autistic people can have difficulties in understanding non-autistic people's mental states such as beliefs, emotions and intentions. Although autistic adults may learn to overcome difficulties in understanding of explicit (overt) mental states, they may nevertheless struggle with implicit (indirect) understanding of mental states. This study explores how spontaneous language is used in order to specifically point to this implicit (indirect) understanding of mental states. In particular, our study compares the spontaneous statements that were used in descriptions of oneself and a familiar other person. Here, we found that autistic and non-autistic adults were comparable in the number of statements about physical traits they made. In contrast, nonautistic adults made more statements about mentalistic traits (about the mental: including psychological traits, relationship traits and statements reflecting about these) both for the self and the other. Non-autistic and autistic adults showed no difference in the number of statements about relationships but in the number of statements about psychological traits and especially in the statements reflecting on these. Each group showed a similar pattern of kinds of statements for the self and for the other person. This suggests that autistic individuals show the same unique pattern of description in mentalistic terms for the self and another person. This study also indicates that investigating spontaneous use of language, especially for statements 
reflecting about mental states, enables us to look into difficulties with implicit (indirect) understanding of mental states. 


\section{Introduction}

Theory of Mind is defined as the capacity to understand and predict mental states such as beliefs, emotions, desires and intentions (Premack \& Woodruff, 1978). The idea that autistic individuals struggle to represent and understand the mental states of others, an ability that is also known as mentalizing, is widely acknowledged and continues to receive much attention and support (Baron-Cohen, 1995; Baron-Cohen, Leslie \& Frith, 1985; Happé, 2015; Senju, 2013; Senju, Southgate, White \& Frith, 2009), yet its ability to serve as a universal explanation of the most characteristic social features and communicative impairments of autism remains contentious (Chevallier, Kohls, Troiani, Brodkin \& Schultz, 2012; Gernsbacher \& Yergeau, 2019; Leekam, 2016). One reason for this controversy is that many autistic individuals are able to pass explicit mentalizing tests (e.g. when prompted to explain what someone thinks; (Happé, 1995; White, Hill, Happé \& Frith, 2009). However, it has long been surmised that successful performance on explicit mentalizing tasks that trigger conscious, controlled and systematic reflective processes (as introduced in dual process theories (Evans \& Stanovich, 2013; Van Overwalle \& Vandekerckhove, 2013)) does not necessarily mean that autistic individuals have acquired full mentalizing, but that their test performance rather relies on some form of compensatory mechanism (Frith, 2004, 2013; Livingston \& Happé, 2017). It seems likely that many autistic individuals learn explicitly about mental states through exposure to mentalistic language, which in turn allows them to use such terms richly in their own language and writing (Grandin, 1986; Mukhopadhyay, 2003; Tammet, 2006; Williams, 1992).

Intriguingly, several eye-tracking studies have now shown that autistic individuals who pass explicit mentalizing tasks still have difficulties in implicit mentalizing tasks requiring 
unconscious, automatic, spontaneous and intuitive processing (Schneider, Slaughter, Bayliss \& Dux, 2013; Schuwerk, Vuori \& Sodian, 2015; Senju et al., 2009) and show atypical mentalizing-related brain activity (White, Frith, Rellecke, Al-Noor \& Gilbert, 2014). This hypothesis that an implicit mentalizing impairment is present in autism would benefit from convergent findings from a broader range of methodological techniques. An alternative and complementary approach is to examine spontaneous speech that is likely to contain mentalistic expressions (Meins \& Charles, 2010); which is the case when asked to reflect on personal characteristics (Kristen, Rossmann \& Sodian, 2014). This technique avoids many of the common issues with explicit measures: participants are not explicitly primed to represent mental states as it is not a 2-alternative forced choice paradigm, it involves open rather than closed questions, these questions are orthogonal to the variable of interest (it assesses the types of language used rather than the answer), it involves real-life rather than fictional information, and it evokes continuous speech which requires fast, online decisions to be made about content which reflect natural tendencies and abilities rather than calculated reasoning.

While the majority of research has focused on differences of implicit mentalizing in autism with respect to other's mental states, there has been a more recent trend to establish whether autistic individuals show a spontaneous tendency to also think of themselves in mentalistic terms. There is currently much debate concerning how the ability to understand one's own mental states may relate to the ability to understand the mental states of other people. Various approaches have been suggested to elucidate the nature of this relationship, ranging from there being two distinct underlying mechanisms (Nichols \& Stich, 2003) to a shared underlying mechanism for mentalizing about own and others' mental states (Frith \& Happé, 1999; Happé, 2003; Leslie, 1987), to either one being prior to the other capacity (Carruthers, 
2009; Goldman, 2006; Gopnik, 1993). Autism thus presents an interesting case by which to study these two abilities and how they might relate to each other. The literature currently points towards there being impairments also for mentalizing about own mental states (Brosnan, Lewton \& Ashwin, 2016; Grainger, Williams \& Lind., 2014, 2016; Hurlburt, Happé \& Frith 1994; Jackson, Skirrow \& Hare, 2012; Lee \& Hobson, 1998; Mitchell \& O’Keefe, 2008; Nicholson, Williams, Grainger, Lind \& Carruthers, 2019; Williams \& Happé, 2009) but implicit tasks and comparable 'self' and 'other' measures have rarely been used. A direct comparison of implicit mentalizing about own and others' mental states is well needed.

In the current study, we therefore examined spontaneous speech production relating both to the self and to a familiar other in directly comparable conditions. As part of a study of episodic versus semantic autobiographical memory, (Kristen et al., 2014) examined spontaneous speech production specifically relating to the self, asking participants: 'can you describe yourself for me?'. They found that autistic adults used fewer 'mental' expressions than typical adults in their free descriptions of themselves (this was a broad category of expressions including comments about interests and intellect as well as feelings and imagination). We took a similar approach, but additionally asked participants to reflect on the personal characteristics of a familiar other and devised a more detailed hierarchical coding system, specifically designed to capture implicit mentalizing.

Analysis of spontaneous speech has likewise been used to investigate the inner experience of adults with autism. A study by Hurlburt et al. (1994); reported in further detail in (Frith \& Happé, 1999) used the descriptive experience sampling method in which three autistic adults were asked to describe their thoughts at unpredictable moments as they went about their daily lives. One notable finding was the absence of self-reflection in these accounts. Further, 
none of these adults ever asked whether the inner states they reported were similar to or different from those of others. This was in marked contrast to non-autistic participants who invariably wondered out loud about their thoughts, whether they said things that were unique to them, e.g. "I am uncertain about how to describe myself", "I wonder what other people say when they talk about themselves?", “Am I answering in the way you expect me to?”. Some of these statements may have been due to reputation management in non-autistic adults, but the majority indicate self-reflective processes. This suggests that the spontaneous production of such meta-statements when talking about own mental states might be a distinctive feature of non-autistic adults. Meta-statements are higher-order representations of a specific content. They can be about a mental state, e.g. a belief (a first-order representation of a state in the world). The meta-representation thus represents a representation, which reflects on the properties of the first. This feature may be absent or less prominent in autistic adults if they have difficulties in implicit mentalizing. Spontaneous production of meta-statements may be a clearer reflection of implicit mentalizing than spontaneous production of mentalistic language, which may result through exposure to such language without a deeper mental state understanding. In the current study, we therefore focussed on such meta-statements by also asking questions that required participants to reflect about what they liked best about themselves or their close other, and what they thought about the experience of the interview.

What kind of spontaneous mentalistic language would we find about the self and about the other in a brief interview period? Would we find spontaneous meta-statements, indicative of reflection on one's own and others' mental states? To answer these questions, our pilot study examined the self and other descriptions of highly verbally-able autistic adults in terms of spontaneous use of mentalistic language and meta-representational utterances, through 
quantitative and qualitative analysis. We expected to see a reduction in mentalistic language in the descriptive accounts given about both the self and a familiar other, but even more so for meta-representational statements.

\section{Methods}

\section{Participants}

Ethical approval for the study was received from the Joint UCL/UCLH committee on the Ethics of Human Research and, before the test session, written informed consent was sought and received from all participants. Twenty-four adults participated in the study: 11 autistic individuals (8 males) and 13 non-autistic comparison participants (9 males). All had completed or were undergoing tertiary education, all but two participants were holding a job, all participants were white. The groups were comparable in terms of age $(\mathrm{t}(22)=0.99, \mathrm{p}=0.331$, $\mathrm{d}=0.407$; see Table 1), gender $\left(\left(\chi^{2}(1)=0.035, \mathrm{p}=1.000, \mathrm{~V}=0.038\right)\right.$ and IQ (FSIQ: $(\mathrm{t}(20)=1.41$, $\mathrm{p}=0.174, \mathrm{~d}=0.588$; IQ data was not available for 2 non-autistic participants). As the difference in VIQ ( $\mathrm{t}(20)=1.486, \mathrm{p}=0.153, \mathrm{~d}=0.616)$ was not small between groups, we used VIQ as a covariate in the analysis in order to control for the possible impact on general verbal abilities.. All participants in the autistic group had been previously diagnosed with Asperger Syndrome by an independent clinician, except for one with a diagnosis of high-functioning autism. On the Autism Diagnostic Observation Schedule (ADOS-G; (Lord, Risi, Lambrecht, Cook, Leventhal, DiLavore, Pickles, \& Rutter, 2000)), four participants met the criteria for autism and six more for autism spectrum. The remaining participant was not excluded as she met ADOS criteria in the social domain but had a physical disability that made it impossible to score the two gesture items in the communication domain. Autism-Spectrum Quotient scores (AQ; (Baron-Cohen, 
Wheelwright, Skinner, Martin, \& Clubley, 2001)) were significantly higher in the autistic group than the comparison group $(\mathrm{t}(20)=4.35, \mathrm{p}=<0.001, \mathrm{~d}=1.363)$. Lastly, the autistic group performed less well on an advanced test of explicit mentalizing (Strange Stories (SSs) mental state set which has been shown to highly correlate with a ToM- battery, thus providing high test validity) (White et al., 2009); $\mathrm{t}(20)=2.22, \mathrm{p}=0.038, \mathrm{~d}=0.870)$.

Table 1 about here

\section{Procedure}

The test session took place at the Institute of Cognitive Neuroscience in London, in the form of an interview, and was conducted by AZ. The interview was recorded and later transcribed. The interview consisted of 4 sections: introductory questions, questions relating to the 'self', questions relating to a close 'other', and closing questions. Participants were prompted with specific questions but also generally encouraged to carry on talking if they gave very short answers, using phrases such as 'tell me a bit more about that'.

1. Introductory questions gave the participant a chance to get used to the setting and style of the interview, and involved factual questions that were expected to be relatively easy to answer. We also included questions relating to friends and family in order to determine who would be the subject of the 'other' questions in section 3 :

- What school did you go to? Did you go to college or university? What qualifications have you got?

- Do you have a job? What kind of a job do you have? If not: How do you spend your time? 
- Do you have brothers or sisters? Do you have a close friend? (If not, use 'mother' for question 3.) When did you last see them?

2. Self-related questions:

- Tell me something about yourself. What kind of a person are you?

- What do you like best about yourself?

3. Other-related questions:

- Tell me something about your close friend/mother. What kind of a person is she/he?

- What do you like best about her/him?

4. Closing questions provided the participant with an opportunity to add any further information they wished and also gave them a chance to give us feedback about their experience of the experiment and to ask any questions they might have.

- Is there anything else you would like to tell me about yourself?

- How did you feel about the interview?

\section{Interview Analysis}

All participants talked for at least 2 minutes each in response to the 'self' questions and to the 'other' questions. We therefore restricted our analysis to these first two minutes of verbal response to the 'self' questions, and to the first two minutes of the 'other' questions.

\section{Coding}

Following the principles of Grounded Theory (Glaser \& Strauss, 1967), the verbal responses were broken down into chunks of information through eight complete cycles of iterative coding in order to refine the classification system and ensure the chunks were consistently categorised. A chunk was considered as a unit of information that contained one idea and its elaboration (see Table 2 for examples). Each chunk was placed into one of the 
following five meaningful and easily distinguishable categories according to the kind of information represented within it. Where a chunk represented more than one category, one category was always clearly central to the information provided and the additional categories were incidental, hence the chunk was assigned to the former category. We iteratively established the following categories:

Physical

- interests (including activities)

- factual (physical traits including job, place of residence etc.)

Mentalistic

- psychological (psychological characteristics and traits)

- relationship (relational statements, or comments involving other people in self-report)

- meta-statement (statements that reflect second-order beliefs and attitudes relating to something being said by the interviewees themselves)

The latter three categories were grouped together as 'mentalistic', as they frequently involved mental state terms and hence may potentially be indicative of an understanding of mental states. Within the relationship category, we further sub-categorised the chunks into those containing information relating to the self-benefit of the relationship, the mutual-benefit of the relationship or those containing neither. Within the meta-statement category comprising second-order beliefs and attitudes, we likewise sub-categorised the chunks into those containing information relating to meta-meta-statements or not: second-order comments on the interviewsituation that reveal an awareness of the self being in a situation where they are talking about themselves. 
There were a few chunks that did not fit in any of the mentalistic or physical categories. These included:

- self-reference intrusions (statements about oneself during the 'other' condition)

- tangential statements (digressions about irrelevant topics)

Finally, we also recorded whether each participant made a meta-statement during section 4 of the interview, when asked how they felt about the interview.

Table 2 about here

\section{Results}

We ran a 2 (target: self/other) by 2 (content: mentalistic/physical) by 2 (group: autistic/ non-autistic) ANCOVA controlling for VIQ on the number of chunks of information produced by each participant across each 2 minute time period. We did not find a main effect of content $\left(\mathrm{F}(1,19)=3.86, \mathrm{p}=0.064, \eta_{\mathrm{p}}{ }^{2}=0.169\right)$ but a clear tendency to produce more chunks relating to mentalistic than physical traits. A main effect of group was observed $(F(1,19)=7.93, p=0.011$, $\left.\eta_{\mathrm{p}}{ }^{2}=0.294\right)$, indicating that the non-autistic group produced more chunks than the autistic group. We did not find a main effect of target $\left(F(1,19)=1.89, p=0.185, \eta_{\mathrm{p}}{ }^{2}=0.091\right)$, with participants producing a rather similar number of chunks in the 'other' and in the 'self' conditions.

Content did not interact with target $\left(\mathrm{F}(1,19)=0.73, \mathrm{p}=0.405, \eta_{\mathrm{p}}{ }^{2}=0.037\right)$ indicating that participants did not differ in the number of chunks relating to physical and mental traits in the 'self' and 'other' conditions.

Especially relevant to this study was the finding that content did interact with group $\left(\mathrm{F}(1,19)=19.84, \mathrm{p}<0.001, \eta_{\mathrm{p}}{ }^{2}=0.511\right.$; see Figure 1). Specifically, the linear regression conducted 
showed that both groups were more similar in the number of chunks they produced relating to physical traits $\left(F(2,19)=1.61, p=0.226, R^{2} \operatorname{adj} .=0.055\right.$; group: $\beta=0.382, t(21)=1.71, p=0.104$; VIQ: $\beta=0.237, \mathrm{t}(21)=1.06, \mathrm{p}=0.302)$ but the non-autistic group clearly produced more chunks relating to mentalistic traits than the autistic group $\left(F(2,19)=8.22, p=0.003, R^{2}\right.$ adj. $=0.407$; group: $\beta=0.710, \mathrm{t}(21)=4.01, \mathrm{p}=0.001$; VIQ: $\beta=0.123, \mathrm{t}(21)=0.70, \mathrm{p}=0.496)$ where VIQ did not contribute to the model. This interaction between content and group was not modulated by target however (3-way interaction: $\left.F(1,19)=0.612, \mathrm{p}=0.444, \eta_{\mathrm{p}}{ }^{2}=0.031\right)$, indicating that the autistic group produced fewer chunks than the non-autistic group about mentalistic traits in both the 'self' and the 'other' conditions.

\section{Insert Figure 1 here}

We further explored this latter finding of group differences in chunks relating to the different mentalistic trait categories. Here, we collapsed the data across the 'self' and 'other' conditions, given that this variable was not modulated by group. We found differences between the non-autistic and autistic groups on the psychological category $(F(2,19)=6.72, p=0.006$, $\mathrm{R}^{2} \mathrm{adj}=0.353$; group: $\left.\beta=0.673, \mathrm{t}(21)=3.64, \mathrm{p}=0.002 ; \mathrm{VIQ}: \beta=0.135, \mathrm{t}(21)=0.73, \mathrm{p}=0.474\right)$ and the meta-statement category $\left(\mathrm{F}(2,19)=4.06, \mathrm{p}=0.034, \mathrm{R}^{2} \mathrm{adj} .=0.226\right.$; group: $\beta=0.547, \mathrm{t}(21)=2.70$, $\mathrm{p}=0,014$; VIQ: $\beta=0.002, \mathrm{t}(21)=0.01, \mathrm{p}=0.993)$ with the non-autistic group consistently producing more chunks than the autistic group, but no substantial difference in the relationship category $\left(\mathrm{F}(2,19)=0.82, \mathrm{p}=0.454, \mathrm{R}^{2} \mathrm{adj} .=0.017\right.$; group: $\beta=0.296, \mathrm{t}(21)=1.28, \mathrm{p}=0.217$; VIQ: $\beta=0.062, \mathrm{t}(21)=0.27, \mathrm{p}=0.217)$. However, breaking down the relationship category we found that, while the non-autistic group produced more chunks relating to the mutual-benefit of the 
relationship category $\left(F(2,19)=4.15, p=0.032, R^{2}\right.$ adj. $=0.231$; group: $\beta=0.527, t(21)=2.61, p$ $=0.017 ;$ VIQ: $\beta=0.067, \mathrm{t}(21)=0.33, \mathrm{p}=0.745)$, the autistic group showed a trend towards producing more chunks relating to the self-benefit of the relationship $(F(2,19)=3.169, p=0.065$, $\mathrm{R}^{2}$ adj. $=0.171$; group: $\beta=0.258, \mathrm{t}(21)=1.23, \mathrm{p}=0.233$; VIQ: $\left.\beta=0.355, \mathrm{t}(21)=1.69, \mathrm{p}=0.107\right)$; all such statements are listed in the supplementary information. Within the meta-statement category, the groups did not differ in the number of meta-meta-statement chunks they produced $(\mathrm{U}=60.0, \mathrm{p}=0.482, \mathrm{r}=0.055)$; these were produced infrequently during this part of the interview (see table 3).

Table 3 about here

The groups did not differ in the number of self-reference intrusions produced $\left(F(2,19)=0.02, p=0.977, R^{2}\right.$ adj. $=0.103$; group: $\beta=0.016, t(21)=0.068, p=0.947 ;$ VIQ: $\beta=0.052$, $\mathrm{t}(21)=0.214, \mathrm{p}=0.833)$. Very few tangential comments were made and the groups again did not $\operatorname{differ}(\mathrm{U}=52.0, \mathrm{p}=0.082, \mathrm{r}=0.082)$.

We also looked at correlations between different measures within the task and with background explicit mentalizing measure (SSs). The number of mentalistic and physical chunks produced did not relate to each other (Non-autistic: $\mathrm{r}=0.051, \mathrm{p}=0.870, \mathrm{r}^{2}=0.003$; autistic: $\left.\mathrm{r}=0.190, \mathrm{p}=0.576, \mathrm{r}^{2}=0.036\right)$. Interestingly, the 'mentalistic self' and 'mentalistic other' conditions did correlate in the non-autistic group $\left(r=0.793, p=0.001, r^{2}=0.629\right)$ but only minimally in the autistic group $\left(\mathrm{r}=0.305, \mathrm{p}=0.362, \mathrm{r}^{2}=0.093\right)$. We did not find a strong correlation between the SSs and the mentalistic condition for the comparison group (Nonautistic: $r=0.327, p=0.326, r^{2}=0.107$; autistic: $r=0.249, p=0.460, r^{2}=0.062$ ), nor between SSs and 
the number of meta-statements (Non-autistic: $r=0.357, p=0.281, r^{2}=0.127$; autistic: $r=0.287$, $\left.\mathrm{p}=0.393, \mathrm{r}^{2}=0.082\right)$.

We followed up our findings from the 2 minute segments by looking at specific time points within those segments. For the 'self' condition, we found that the non-autistic group were more likely than the autistic group to give a psychological trait as their first statement about themselves $\left(77 \%\right.$ vs $36 \% ;\left(\chi^{2}(1)=4.003, p=0.045, V=0.410\right)$, whereas the groups did not clearly differ in the frequency with which they gave a psychological trait as the thing they liked best about themselves $\left(100 \%\right.$ vs $91 \% ;\left(\chi^{2}(1)=1.233, p=0.267, V=0.227\right)$. Within these statements about what participants liked best about themselves, we found that the non-autistic group was more likely to give psychological social traits (e.g. compassionate, loyal) as their first statement ( $85 \%$ vs $46 \%$ ), whereas the autistic group was more likely to give psychological nonsocial statements (e.g. ambitious, logical) about themselves $\left(15 \%\right.$ vs $55 \% ; \chi^{2}(1)=4.112$, $\mathrm{p}=0.043, \mathrm{~V}=0.414 ;$ see table $4 \mathrm{a})$.

For the 'other' condition, we found that both groups were just as likely to give psychological traits as their first statement $\left(31 \%\right.$ vs $27 \% ;\left(\chi^{2}(1)=0.035, p=0.851, \mathrm{~V}=0.038\right)$ or a statement about the relationship to the 'other' (39\% vs $36 \% ;\left(\chi^{2}(1)=0.11, p=0.916, V=0.022\right)$. The groups also did not differ in the frequency with which they gave a psychological trait as the thing they liked best about the 'other' (46\% vs $36 \%$ ) or a statement about the relationship to the 'other' ( $54 \%$ vs $64 \% ; \chi^{2}(1)=0.235, \mathrm{p}=0.628, \mathrm{~V}=0.099$; see table $\left.4 \mathrm{~b}\right)$. Groups also did not differ in referring to psychological social traits (e.g. friendly, socially gregarious) (38\% vs $27 \%$, $\chi^{2}(1)=0.336, p=0.562, V=0.118$; see table $\left.4 b\right)$ or in the likelihood of giving a psychological non-social trait $\left(8 \%\right.$ vs $\left.9 \%, \chi^{2}(1)=0.015, \mathrm{p}=0.902, \mathrm{~V}=0.025\right)$ as a first statement about what they liked best about the 'other'. 
Insert tables $4 \mathrm{a}$ and $4 \mathrm{~b}$ about here

Finally, at the end of the interview in question 4, more non-autistic than autistic participants made a meta-statement $\left(69 \%\right.$ vs $18 \% ;\left(\chi^{2}(1)=6.254, \mathrm{p}=0.012, \mathrm{~V}=0.510\right)$ or a metameta-statement $\left(69 \%\right.$ vs $0 \% ;\left(\chi^{2}(1)=12.186, \mathrm{p}<0.001, \mathrm{~V}=0.713\right)$ relating to their experience of the interview. A list of all meta-statements made by participants in both groups is given in the supplementary information given that the richness of the interviews is hard to capture in the quantitative analysis.

\section{Discussion}

In the present study, we examined spontaneous personal descriptions of highly verballyable autistic individuals and compared them to those of non-autistic adults. When asked to reflect on their own and a close other's personal characteristics, mental state expressions are frequently spontaneously produced that provide an insight into the functioning of the mentalizing system. We were interested in the kinds of mentalistic language that would be used, and whether and how these reports would differ with respect to the 'self' and the 'other'. We were especially keen to detail the use of meta-statements as a more direct measure of implicit mentalizing.

Even though both groups spontaneously produced more mentalistic than physical statements and produced a similar number of chunks relating to physical traits, our main empirical finding was that the autistic adults produced significantly fewer chunks involving mentalistic language for both the 'self' and 'other' condition, consistent with (Kristen et al., 2014) 'self' findings. This indicates that autistic participants are less likely to represent mental 
states (White, Coniston, Rogers, \& Frith, 2011) or have a more general difficulty of understanding of conversational expectations to talk about mental traits, being unaware of what the interviewer expects to hear (Ochs, Kremer-Sadlik, Sirota \& Solomon, 2004) or being indifferent to conforming to this imposed standard (Cage, Pellicano, Shah \& Bird, 2013). Either way, as the differences were present in both 'self' and 'other' conditions, the difficulty appears to lie in implicitly mentalizing in the same way as non-autistic participants in terms of both theory of own and theory of other mind. This may also be regarded as an indicator for the same metarepresentational process underlying the representation of own and others' mental states. With regard to the self, the notion of a distinction between physical and psychological selfawareness in ASD is also supported (Lind, 2010; Uddin, 2011; Uddin, Iacoboni, Lange \& Keenan 2007).

Considering the different types of mentalistic statement produced, the autistic group made a similar number of statements about relationships to the non-autistic group, but fewer chunks about psychological traits and meta-statements. The social interaction difficulties associated with autism may lead us to think that the desire for relationship is reduced (Chevallier et al., 2012) but our results indicate that such relationships are given high importance in the mentalistic description of other people in spontaneous speech; this is in keeping with a recent study showing high implicit desire for social interaction in autism despite low explicit self-report (Deckers, Roelofs, Muris \& Rinck, 2014) and with criticism of the social motivation hypothesis (Jaswal \& Akhtar, 2018). The distinction between self-benefitting and mutual aspects helps to shed light on the nature of these relationships: autistic participants produced slightly more chunks than the non-autistic adults relating to the self-benefit of the relationship while the non-autistic group relayed more about the mutual-benefit of the 
relationship than the autistic group. In addition, the non-autistic adults were just as likely to make self-reference intrusions as the autistic adults. Thus, we seem to find a more egocentric perspective specifically on relationships in autistic participants (Frith \& de Vignemont, 2005), consistent with difficulties adopting others' mental perspectives, and/or perhaps a realistic view of such relationships given their social difficulties (Müller, Schuler \& Yates, 2008).

We were similarly able to explore the reduction in statements about psychological states in the autistic group. Autistic participants were less likely to give a psychological trait as their first statement about themselves, indicating that mental states are less strongly represented by autistic adults or are given lower priority. Although the groups did not differ in the frequency with which they gave a psychological trait as the trait they liked best about themselves, the nonautistic group were more likely to make social-psychological statements (e.g. compassionate, loyal) whereas the autistic group tended to make non-social psychological statements (e.g. ambitious, logical). This indicates that non-social psychological traits are either more important or are personal areas of strength for autistic participants in comparison to their social difficulties. The groups did not differ however in the likelihood of giving a psychological statement or a statement about the relationship as the first or best trait they liked about the 'other'. This further highlights the importance of these relationships in both groups; although psychological terms were used less often in the autistic group, they were just as likely to be prioritised as either the first statement or the thing they liked best about the 'other'.

We were particularly struck by the substantial reduction in spontaneous meta-statement production as well as meta-meta-statement use, consistent with Hurlburt et al's findings (Hurlburt et al., 1994), as these provided a more direct index of mental state understanding. While other mental utterances made during the interview reveal a tendency to spontaneously use 
mentalistic language, they only indirectly point towards a reliance on mental representation. Meta-statements, on the other hand, provide direct evidence of mentalizing, relying on $2^{\text {nd }}$ order mental representations (Leslie, 1987). As can be seen in the supplementary information, the non-autistic adults seemed to reflect more freely and effortlessly in spontaneous metastatements about their own personalities and relationships, and the difficulties of speaking about themselves, as well as the structure and content of the interview situation itself. In contrast, autistic individuals made very few spontaneous meta-statements, and these mainly concerned the experience of being autistic. When asked how they felt about the interview, the autistic group did not reflect on the awkwardness or potential difficulties generated by self-disclosure while in a stranger-intimacy-dichotomy, or on the chance to and difficulty of self-reflecting through the interview, whereas the non-autistic participants frequently produced such metameta-statements. These differences may point to a lack of awareness of one's own experience (Frith \& Happé, 1999), or a lack of insight into the experimenter's expectation in asking the question (White, 2013). Instead of seeing the question as an opportunity to feedback on their personal experience, autistic participants may have interpreted the question ("how did you feel about the interview?") as being about emotion; they certainly did provide feedback, saying that the interview was generally alright. Moreover, autistic individuals may have found the interview questions to be less of an imposition, may have been less aware of the possible negative implications of sharing personal information, and hence may not have attempted to manage their reputation even though possible (Cage et al., 2013; Frith \& Frith, 2008; Frith \& Frith, 2011; Izuma, Matsumoto, Camerer \& Adolphs , 2011). Taken together, it is likely that this reduction in spontaneous meta-statement production by autistic participants points to an 
underlying difficulty in representing both own and others' mental states and reflecting on them, thus exhibiting less implicit mentalizing.

How can we explain the lack of association between spontaneous mentalistic language and standard tests of mentalizing? The test we used was designed to detect mentalizing difficulties in older and more verbally-able individuals (Happé, 1994) but, as a measure of explicit mentalizing, is subject to compensatory processes (Frith, 2004, 2013; Livingston \& Happé, 2017). Indeed, while the autistic adults performed more poorly than the non-autistic group on this test, they still gave correct answers to the majority of items (12 out of 16). Explicit tests may thus provide a surface measure of mentalizing, indexing the degree of compensatory learning achieved, rather than of deep mentalizing ability (Sonuga-Barke, 2016). On the other hand, our measure of spontaneous mentalistic language is likely to provide a cleaner proxy for implicit mentalizing ability and hence these two measures might well be expected to be independent. Future studies could instead assess the relationship between the spontaneous production of mentalistic language and implicit mentalizing measures such as eye tracking tasks (Senju et al., 2009). The measure of spontaneous production of mentalistic language is further supported by the concept of the process of metacognition not being conscious and intentional but as being a representational re-description based on unconsciously and automatically occurring of meta-representational processes (Timmermans, Schilbach, Pasquali \& Cleeremans, 2012).

The openness of this pilot study, the spontaneous speech and its analysis present a challenge but are concurrently its most exciting feature. It is fascinating to see how an individual approaches the very general question to talk about oneself and this technique has the potential to provide insight into implicit mentalizing that more restricted settings lack. 
While the sample data collected is of good quality and its size big enough to allow new and rich textual understanding of the phenomenon under study (Sandelowski, 1995), there are limitations of only having tested small groups of participants with regards to the statistical power, reliability and generalizability of our results. Although the complex ANCOVA showed significant main effects despite small sample size it is nevertheless possible that other results have not been found that may counter our hypothesis. The difference in verbal IQ $(\mathrm{p}=0.153$, $\mathrm{d}=0.616$ ) between groups while analysing spontaneous language production presents a further limitation, which we accounted for by using VIQ as a co-variate in our analysis. The interaction between content and group remained stable despite the covariate which did not have an effect on the performance of the groups on the production of mentalistic chunks. This strengthens the finding of the difference in the production of mentalistic but not physical chunks that is not dependent on differences in VIQ. Thus, even with this small number we find clear tendencies in support of mentalizing difficulties relating to both own and others' minds in autism.

We believe that we made a significant contribution to this field as something along these lines has to our knowledge not yet been published. From a clinical perspective, our approach to implicit mentalizing that is not susceptible to compensatory learning, may be developed into a valuable basic tool for diagnostic tests of self-awareness and mentalizing, targeting both the group of high-functioning ASD and non-autistic adults.

In summary, our findings suggest that autistic individuals, who are less prone to use spontaneous mentalistic language and make fewer meta-statements, show an atypical pattern of mental state representation for both self and other. While autistic and non-autistic adults were comparable in the production of physical statements, the latter group did go into greater depth and density in terms of their mentalistic descriptions. Despite the prominence given to 
relationships in both groups, autistic adults focussed more on self-beneficial than mutual aspects. Although psychological traits were equally valued in both groups, autistic adults mentioned such traits less frequently and were more likely to focus on non-social than social characteristics. Meta-statements in particular add a degree of complexity to these descriptions and to the understanding of mental states, which was reduced in autism. The study of spontaneous speech thus provides a novel means by which to gain insight into implicit mentalizing in autism. 
Abbreviations

ADOS-G: Autism Diagnostic Observation Schedule; ASD: Autism Spectrum Disorder; AQ:

Autism Spectrum Quotient; SSs: Strange stories- mental state set

\section{Acknowledgements}

The authors would like to thank all of the participants who took part in this study. We would like to also thank Oron Shagrir, Vera Hoffmann-Kolss, Antje Riepenhausen and Axel Horst for helpful comments and discussion.

The research was supported by grants from the German Academic Scholarship Foundation (Studienstiftung des deutschen Volkes) and the Minerva Foundation (Max-PlanckGesellschaft) (AZ) and by the Royal Society (Dorothy Hodgkin Research Fellowship DH150167).

\section{Appendix. Supplementary Material}




\section{References}

Baron-Cohen, S. (1995). Mindblindness: An Essay on Autism and Theory of Mind. MIT Press.

Baron-Cohen, S., Leslie, A. M., \& Frith, U. (1985). Does the autistic child have a "theory of mind" ? Cognition, 21(1), 37-46. DOI:10.1016/0010-0277(85)90022-8

Baron-Cohen, S., Wheelwright, S., Skinner, R., Martin, J., \& Clubley, E. (2001). The AutismSpectrum Quotient (AQ): Evidence from Asperger Syndrome/High-Functioning Autism, Males and Females, Scientists and Mathematicians. Journal of Autism and Developmental Disorders, 31(1), 5-17. DOI:10.1023/A:1005653411471

Brosnan, M., Lewton, M., \& Ashwin, C. (2016). Reasoning on the Autism Spectrum: A Dual Process Theory Account. Journal of Autism and Developmental Disorders, 46, 21152125. DOI:10.1007/s10803-016-2742-4

Cage, E., Pellicano, E., Shah, P., \& Bird, G. (2013). Reputation management: Evidence for ability but reduced propensity in autism. Autism Research: Official Journal of the International Society for Autism Research, 6(5), 433-442. DOI:10.1002/aur.1313

Carruthers, P. (2009). How we know our own minds: The relationship between mindreading and metacognition. Behavioral and Brain Sciences, 32(2), 121-138.

DOI:10.1017/S0140525X09000545

Chevallier, C., Kohls, G., Troiani, V., Brodkin, E. S., \& Schultz, R. T. (2012). The Social Motivation Theory of Autism. Trends in Cognitive Sciences, 16(4), 231-239.

DOI:10.1016/j.tics.2012.02.007

Deckers, A., Roelofs, J., Muris, P., \& Rinck, M. (2014). Desire for social interaction in children with autism spectrum disorders. Research in Autism Spectrum Disorders, 8(4), 449-453. DOI:10.1016/j.rasd.2013.12.019 
Evans, J. S. B. T., \& Stanovich, K. E. (2013). Dual-Process Theories of Higher Cognition: Advancing the Debate. Perspectives on Psychological Science.

DOI:10.1177/1745691612460685

Frith, C. D., \& Frith, U. (2008). The Self and Its Reputation in Autism. Neuron, 57(3), 331-332. DOI:10.1016/j.neuron.2008.01.014

Frith, U. (2004). Emanuel Miller lecture: Confusions and controversies about Asperger syndrome. Journal of Child Psychology and Psychiatry, 45(4), 672-686.

DOI:10.1111/j.1469-7610.2004.00262.x

Frith, U. (2013). Autism and Dyslexia: A Glance Over 25 Years of Research. Perspectives on Psychological Science, 8(6), 670-672. DOI:10.1177/1745691613507457

Frith, U., \& de Vignemont, F. (2005). Egocentrism, allocentrism, and Asperger syndrome. Consciousness and Cognition, 14(4), 719-738. DOI:10.1016/j.concog.2005.04.006

Frith, U., \& Frith, C. (2011). Reputation Management: In Autism, Generosity Is Its Own Reward. Current Biology, 21(24), R994-R995. DOI:10.1016/j.cub.2011.11.001

Frith, U., \& Happé, F.G.E. (1999). Theory of Mind and Self-Consciousness: What Is It Like to Be Autistic? Mind \& Language, 14(1), 82-89. DOI:10.1111/1468-0017.00100

Gernsbacher, M., \& Yergeau, M. (2019). Empirical Failures of the Claim That Autistic People Lack a Theory of Mind. Archives of Scientific Psychology, 7, 102-118. DOI: $10.1037 / \operatorname{arc} 0000067$

Glaser, B. \& Strauss, A. (1967). The discovery of grounded theory: Strategies for qualitative research. Aldine.

Goldman, A. I. (2006). Simulating Minds: The Philosophy, Psychology, and Neuroscience of Mindreading. Oxford University Press. 
Gopnik, A. (1993). How We Know Our Minds: The Illusion of First-Person Knowledge of Intentionality. Behavioral and Brain Sciences, 16(1), DOI:10.1017/S0140525X00028636

Grainger, C., Williams, D. M., \& Lind, S. E. (2014). Metacognition, metamemory, and mindreading in high-functioning adults with autism spectrum disorder. Journal of Abnormal Psychology, 123(3), 650-659. DOI:10.1037/a0036531

Grainger, C., Williams, D. M., \& Lind, S. E. (2016). Metacognitive monitoring and control processes in children with autism spectrum disorder: Diminished judgement of confidence accuracy. Consciousness and Cognition, 42, 65-74.

DOI:10.1016/j.concog.2016.03.003

Grandin, T. (1986). Emergence: Labeled Autistic. Arena Press.

Happé, F.G.E. (2003). Theory of Mind and the Self. Annals of the New York Academy of Sciences, 1001(1), 134-144. DOI:10.1196/annals.1279.008

Happé, F.G.E. (2015). Autism as a neurodevelopmental disorder of mind-reading. Journal of the British Academy, 3, 197-209. DOI:10.5871/jba/003.197

Happé, F.G.E. (1995). The role of age and verbal ability in the theory of mind task performance of subjects with autism. Child Development, 66(3), 843-855. DOI: 10.1111/j.14678624.1995.tb00909.x

Happé, F. G. E. (1994). An advanced test of theory of mind: Understanding of story characters' thoughts and feelings by able autistic, mentally handicapped, and normal children and adults. Journal of Autism and Developmental Disorders, 24(2), 129-154.

DOI:10.1007/BF02172093 
Hurlburt, R. T., Happé, F.G.E., \& Frith, U. (1994). Sampling the form of inner experience in three adults with Asperger syndrome. Psychological Medicine, 24(2), 385-395. DOI:10.1017/s0033291700027367

Izuma, K., Matsumoto, K., Camerer, C. F., \& Adolphs, R. (2011). Insensitivity to social reputation in autism. Proceedings of the National Academy of Sciences, 108(42), 1730217307. DOI:10.1073/pnas.1107038108

Jackson, P., Skirrow, P., \& Hare, D. J. (2012). Asperger Through the Looking Glass: An Exploratory Study of Self-Understanding in People with Asperger's Syndrome. Journal of Autism and Developmental Disorders, 42(5), 697-706. DOI:10.1007/s10803-011$1296-8$

Jaswal, V. K., \& Akhtar, N. (2018). Being vs. Appearing Socially Uninterested: Challenging Assumptions about Social Motivation in Autism. The Behavioral and Brain Sciences, 184. DOI:10.1017/S0140525X18001826

Kristen, S., Rossmann, F., \& Sodian, B. (2014). Theory of own mind and autobiographical memory in adults with ASD. Research in Autism Spectrum Disorders, 8(7), 827-837. DOI:10.1016/j.rasd.2014.03.009

Lee, A., \& Hobson, R. P. (1998). On developing self-concepts: A controlled study of children and adolescents with autism. Journal of Child Psychology and Psychiatry, and Allied Disciplines, 39(8), 1131-1144. DOI:10.1111/1469-7610.00417

Leekam, S. (2016). Social cognitive impairment and autism: What are we trying to explain? Philosophical Transactions of the Royal Society of London. Series B, Biological Sciences, 371(1686), 20150082. DOI:10.1098/rstb.2015.0082 
Leslie, A. M. (1987). Pretense and Representation: The Origins of "Theory of Mind.” Psychological Review, 94(4), 412-426. DOI:10.1037//0033-295X.94.4.412

Lind, S. E. (2010). Memory and the self in autism: A review and theoretical framework. Autism: The International Journal of Research and Practice, 14(5), 430-456. DOI: $10.1177 / 1362361309358700$

Livingston, L. A., \& Happé, F.G.E.. (2017). Conceptualising compensation in neurodevelopmental disorders: Reflections from autism spectrum disorder. Neuroscience and Biobehavioral Reviews, 80, 729-742. DOI:10.1016/j.neubiorev.2017.06.005

Lord, C., Risi, S., Lambrecht, L., Cook, E. H., Leventhal, B. L., DiLavore, P. C., Pickles, A., \& Rutter, M. (2000). The Autism Diagnostic Observation Schedule-Generic: A Standard Measure of Social and Communication Deficits Associated with the Spectrum of Autism. Journal of Autism and Developmental Disorders, 30(3), 205-223.

DOI:10.1023/A:1005592401947

Meins, E. \& Fernyhough, C. (2010). Mind-mindedness coding manual. https://www.york.ac.uk/media/psychology/mindmindedness/MM\%20manual\%20version\%202.2-2.pdf

Mitchell, P., \& O'Keefe, K. (2008). Brief report: Do individuals with autism spectrum disorder think they know their own minds? Journal of Autism and Developmental Disorders, 38(8), 1591-1597. DOI:10.1007/s10803-007-0530-x

Mukhopadhyay, T. R. (2003). The Mind Tree: A Miraculous Child Breaks the Silence of Autism. Arcade Publishing.

Müller, E., Schuler, A., \& Yates, G. B. (2008). Social challenges and supports from the perspective of individuals with Asperger syndrome and other autism spectrum 
disabilities. Autism: The International Journal of Research and Practice, 12(2), 173190. DOI:10.1177/1362361307086664

Nichols, S., \& Stich, S. P. (2003). Mindreading: An Integrated Account of Pretence, SelfAwareness, and Understanding Other Minds. Oxford University Press. http://www.oxfordscholarship.com/view/10.1093/0198236107.001.0001/acprof9780198236108

Nicholson, T., Williams, D. M., Grainger, C., Lind, S. E., \& Carruthers, P. (2019). Relationships between implicit and explicit uncertainty monitoring and mindreading: Evidence from autism spectrum disorder. Consciousness and Cognition, 70, 11-24.

DOI:10.1016/j.concog.2019.01.013

Ochs, E., Kremer-Sadlik, T., Sirota, K. G., \& Solomon, O. (2004). Autism and the Social World: An Anthropological Perspective. Discourse Studies, 6(2), 147-183. DOI: $10.1177 / 1461445604041766$

Premack, D., \& Woodruff, G. (1978). Does the chimpanzee have a theory of mind? Behavioral and Brain Sciences, 1(4), 515-526. DOI:10.1017/S0140525X00076512

Sandelowski, M. (1995). Sample size in qualitative research. Research in Nursing \& Health, 18(2), 179-183. DOI:10.1002/nur.4770180211

Schneider, D., Slaughter, V. P., Bayliss, A. P., \& Dux, P. E. (2013). A temporally sustained implicit theory of mind deficit in autism spectrum disorders. Cognition, 129(2), 410 417. DOI:10.1016/j.cognition.2013.08.004

Schuwerk, T., Vuori, M., \& Sodian, B. (2015). Implicit and explicit Theory of Mind reasoning in autism spectrum disorders: The impact of experience. Autism: The International Journal of Research and Practice, 19(4), 459-468. DOI:10.1177/1362361314526004 
Senju, A. (2013). Atypical development of spontaneous social cognition in autism spectrum disorders. Brain and Development, 35(2), 96-101. DOI:10.1016/j.braindev.2012.08.002

Senju, A., Southgate, V., White, S., \& Frith, U. (2009). Mindblind eyes: An absence of spontaneous theory of mind in Asperger syndrome. Science (New York, N.Y.), 325(5942), 883-885. DOI:10.1126/science.1176170

Sonuga-Barke, E. (2016). Editorial: Distinguishing between the challenges posed by surface and deep forms of heterogeneity to diagnostic systems: Do we need a new approach to subtyping of child and adolescent psychiatric disorders. Journal of Child Psychology and Psychiatry, 57, 1-3. DOI:10.1111/jcpp.12506

Tammet, D. (2006). Born On A Blue Day: Inside the Extraordinary Mind of an Autistic Savant. Hodder and Stoughton.

Timmermans, B., Schilbach, L., Pasquali, A., \& Cleeremans, A. (2012). Higher-order thoughts in action: Consciousness as an unconscious re-description process. Philosophical Transactions of the Royal Society of London. Series B: Biological Sciences, 367(1594), 1412-1423. DOI:10.1098/rstb.2011.0421

Uddin, L. Q. (2011). The self in autism: An emerging view from neuroimaging. Neurocase, 17(3), 201-208. DOI:10.1080/13554794.2010.509320

Uddin, L. Q., Iacoboni, M., Lange, C., \& Keenan, J. P. (2007). The self and social cognition: The role of cortical midline structures and mirror neurons. Trends in Cognitive Sciences, 11(4), 153-157. DOI:10.1016/j.tics.2007.01.001

Van Overwalle, F., \& Vandekerckhove, M. (2013). Implicit and explicit social mentalizing: Dual processes driven by a shared neural network. Frontiers in Human Neuroscience, 7. DOI:10.3389/fnhum.2013.00560 
White, S., Hill, E., Happé, F.G.E., \& Frith, U. (2009). Revisiting the strange stories: Revealing mentalizing impairments in autism. Child Development, 80(4), 1097-1117.

DOI:10.1111/j.1467-8624.2009.01319.x

White, S. J. (2013). The Triple I Hypothesis: Taking Another('s) Perspective on Executive Dysfunction in Autism. Journal of Autism and Developmental Disorders, 43(1), 114121. DOI:10.1007/s 10803-012-1550-8

White, S. J., Coniston, D., Rogers, R., \& Frith, U. (2011). Developing the Frith-Happé animations: A quick and objective test of Theory of Mind for adults with autism. Autism Research: Official Journal of the International Society for Autism Research, 4(2), 149154. DOI:10.1002/aur.174

White, S. J., Frith, U., Rellecke, J., Al-Noor, Z., \& Gilbert, S. J. (2014). Autistic adolescents show atypical activation of the brain's mentalizing system even without a prior history of mentalizing problems. Neuropsychologia, 56, 17-25.

DOI:10.1016/j.neuropsychologia.2013.12.013

Williams, D. (1992). Nobody Nowhere: The Extraordinary Autobiography of an Autistic. Times Books.

Williams, D. M., \& Happé, F.G.E. (2009). What did I say? Versus what did I think? Attributing false beliefs to self amongst children with and without autism. Journal of Autism and Developmental Disorders, 39(6), 865-873. DOI:10.1007/s10803-009-0695-6 


\section{Tables}

Table 1. Mean (and standard deviations) for the non-autistic and autistic groups on background measures (WAIS-IV).

\begin{tabular}{lcc}
\hline & Non-Autistic $(\mathrm{n}=13)$ & Autistic $(\mathrm{n}=11)$ \\
\hline Gender (M:F) & $9: 4$ & $8: 3$ \\
Age (years) & $37(7.69)$ & $33(11.83)$ \\
VIQ $^{+}$ & $116(9.49)$ & $107(17.70)$ \\
PIQ & $113(14.87)$ & $106(12.75)$ \\
FSIQ $^{+}$ & $115(10.02)$ & $107(16.42)$ \\
ADOS total score & - & $9(2.28)$ \\
AQ $* * *++$ & $21(7.68)$ & $36(8,38)$ \\
SSs - mental state set $*++$ & $14(1.22)$ & $12(2.12)$ \\
$*$ p $<0.05, * * *$ p $<0.001,+\mathrm{d}>0.5,^{++} \mathrm{d}>0.8,{ }^{+++} \mathrm{d}>1.0$ &
\end{tabular}


Table 2. Examples of statements falling into the different categories

\begin{tabular}{|c|c|c|}
\hline Category & Non-Autistic & Autistic \\
\hline Interests & $\begin{array}{l}\text { My interests are more in sort of } \\
\text { sampling different things life has to } \\
\text { offer which is why London still has } \\
\text { an enormous appeal to me. }\end{array}$ & $\begin{array}{l}\text { I have a lot of quite technical } \\
\text { interests, like in computers and in } \\
\text { games. }\end{array}$ \\
\hline Factual & $\begin{array}{l}\text { I am } 39 \text { years old, I have lived in } \\
\text { London for } 18 \text { years. }\end{array}$ & I am [name]. I am 23 years old. \\
\hline Psychological & $\begin{array}{l}\text { I am better at it now as I have got } \\
\text { older but I never used to express my } \\
\text { emotions very much with people. }\end{array}$ & $\begin{array}{l}\text { I think I am sort of a fairly ambitious } \\
\text { person, I tend to be quite perseverant } \\
\text { and one sort of thing on my mind. }\end{array}$ \\
\hline Relationship & $\begin{array}{l}\text { So we can talk about anything, } \\
\text { which is good. }\end{array}$ & $\begin{array}{l}\text { Well, he is very cheerful; we have } \\
\text { similar interests. He is interested in } \\
\text { action films as well. }\end{array}$ \\
\hline - Self benefit & $\begin{array}{l}\text { Her loyalty, that is what I like the } \\
\text { best. }\end{array}$ & $\begin{array}{l}\text { I am comfortable with her. And she } \\
\text { does not judge, which is important. }\end{array}$ \\
\hline - Mutual benefit & $\begin{array}{l}\text { I don't know, she just gets me. We } \\
\text { just get each other. We have a great } \\
\text { understanding of each other and I } \\
\text { suppose her loyalty and I guess the } \\
\text { trust we have built up over the years } \\
\text { through our friendship which is, you } \\
\text { know, something I never take for } \\
\text { granted. }\end{array}$ & $\begin{array}{l}\text { Well, we get on well together. Let us } \\
\text { say, he is always smiling. We enjoy } \\
\text { the same things, so we will often play } \\
\text { games on the consoles, play games on } \\
\text { it or watch DVDs when we are at } \\
\text { each other's houses. }\end{array}$ \\
\hline Meta-statement & $\begin{array}{l}\text { (In response to 'what do you like } \\
\text { best about yourself':) Interesting } \\
\text { question. It forces people to be } \\
\text { immodest (laughs). I am great. }\end{array}$ & $\begin{array}{l}\text { I suppose people always say that you } \\
\text { are supposed to say the truth but it is } \\
\text { not really like that. You are not } \\
\text { supposed to do that actually. }\end{array}$ \\
\hline - Meta-meta-statement & $\begin{array}{l}\text { Yeah, it was a bit weird, I don't } \\
\text { know, I do not presume I have to be } \\
\text { interesting. I could just be silent the } \\
\text { whole time and you would have to } \\
\text { kind of deal with it (laughs). }\end{array}$ & - \\
\hline
\end{tabular}


Table 3. Means (and standard deviations) for the two groups of participants of the number of chunks produced in the first 2 minute segments of the 'self' and 'other' conditions, categorised by content

\begin{tabular}{lcc}
\hline & Non-autistic & Autistic \\
\hline Self & & \\
\hline Physical & $4.00(3.46)$ & $5.45(2.34)$ \\
Interests & $2.46(2.93)$ & $3.72(2.10)$ \\
Factual & $1.54(1.39)$ & $1.72(1.95)$ \\
Mentalistic & $11.00(5.46)$ & $5.36(3.91)$ \\
Psychological & $7.23(3.72)$ & $3.27(3.38)$ \\
Relationship & $1.62(2.29)$ & $1.09(1.22)$ \\
$\quad$ Relationship self-benefit & $0.08(0.28)$ & $0.00(.00)$ \\
Relationship mutual-benefit & $0.23(0.83)$ & $0.00(.00)$ \\
Meta-statement & $2.15(1.28)$ & $1.00(1.00)$ \\
$\quad$ Meta-meta-statement & $0.23(0.44)$ & $0.00(0.00)$ \\
Tangential & $0.00(0.00)$ & $0.27(0.47)$ \\
\hline Other & & \\
\hline Physical & $2.54(1.20)$ & $3.45(2.25)$ \\
Interests & $0.62(0.77)$ & $1.55(1.21)$ \\
Factual & $1.92(1.11)$ & $1.91(1.58)$ \\
Mentalistic & $13.92(4.39)$ & $8.54(4.18)$ \\
Psychological & $6.85(3.13)$ & $3.64(3.11)$ \\
Relationship & $5.69(3.47)$ & $4.45(3.53)$ \\
$\quad$ Relationship self-benefit & $0.46(0.52)$ & $1.64(1.96)$ \\
Relationship mutual-benefit & $1.85(1.32)$ & $0.18(0.40)$ \\
Meta-statement & $1.38(0.96)$ & $0.45(0.69)$ \\
$\quad$ Meta-meta-statement & $0.00(0.00)$ & $0.00(0.00)$ \\
Self-reference intrusions & $0.77(0.93)$ & $0.64(0.92)$ \\
Tangential & $0.00(0.00)$ & $0.00(0.00)$ \\
\hline
\end{tabular}


Table 4a. First thing and best thing about 'self'

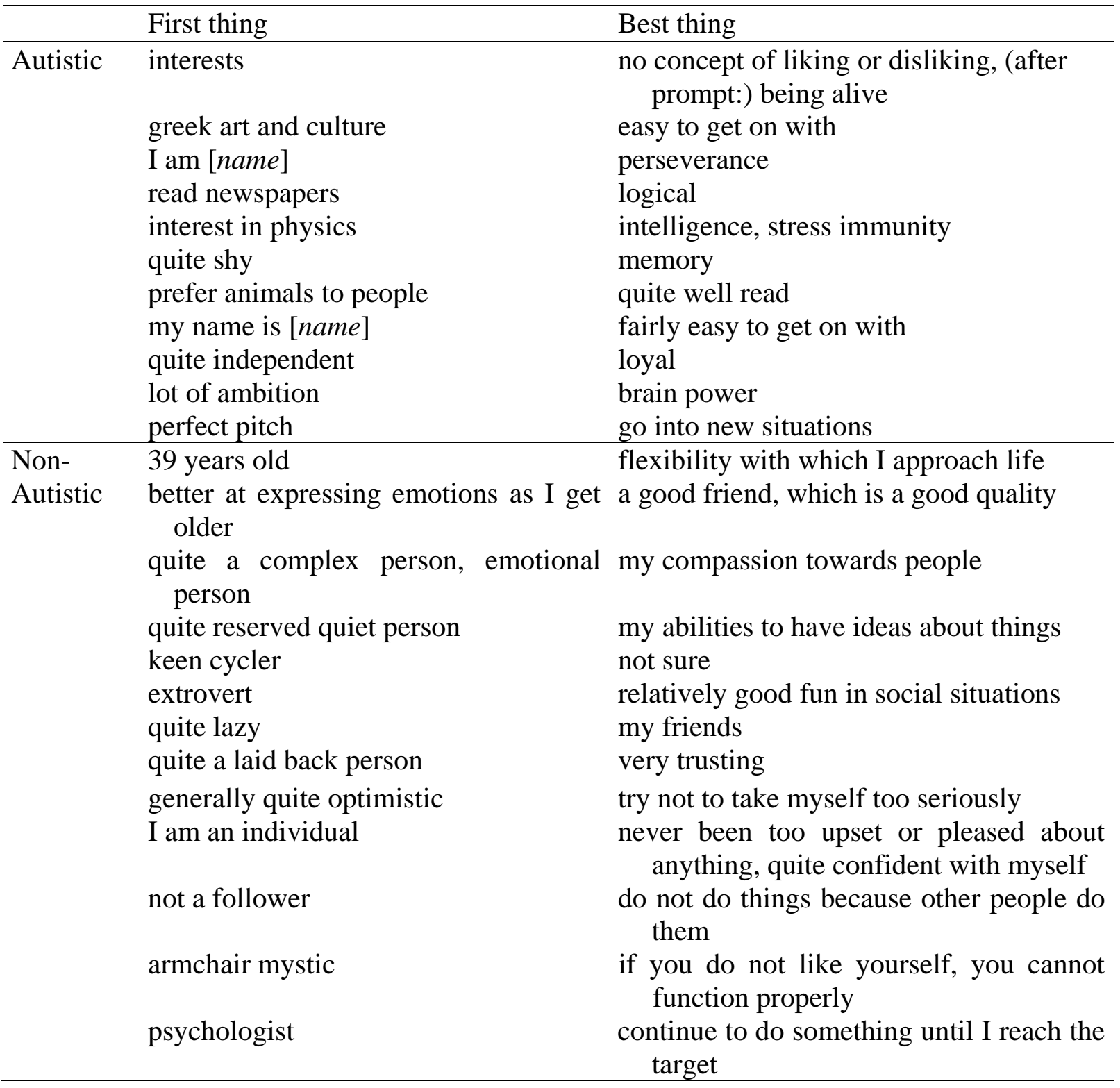


Table 4b. First thing and best thing about 'other', where the other was a mother/father in two cases for the autistic group.

\begin{tabular}{|c|c|c|}
\hline & First thing & Best thing \\
\hline Autistic & $\begin{array}{l}\text { deputy headmaster } \\
\text { strong person } \\
\text { closer to the average sort of person } \\
\text { medical doctor } \\
\text { Cheerful } \\
\text { met at college } \\
\text { finishing her PhD } \\
\text { fairly close friend with whom I work } \\
\text { quite controlling } \\
\text { he is a guy, he is alright } \\
\text { just my oldest friend really }\end{array}$ & $\begin{array}{l}\text { has not disowned me } \\
\text { funny and humorous } \\
\text { copies me in many ways } \\
\text { friendly } \\
\text { get on well together } \\
\text { willing to do stuff } \\
\text { I am comfortable with her } \\
\text { does not judge } \\
\text { not sure I like her very much } \\
\text { resilient } \\
\text { easy-going }\end{array}$ \\
\hline \multirow{6}{*}{$\begin{array}{l}\text { Non- } \\
\text { Autistic }\end{array}$} & very smart woman & her loyalty \\
\hline & $\begin{array}{l}\text { we went to the same primary school } \\
\text { good sense of humor } \\
\text { also an artist } \\
\text { relatively new friend } \\
\text { university lecturer in French } \\
\text { his name is [name] } \\
\text { quite similar to me } \\
\text { have known [name] for almost } 18 \text { years }\end{array}$ & $\begin{array}{l}\text { I like that we go way back } \\
\text { his trust in me } \\
\text { unfeasible } \\
\text { funny and interesting } \\
\text { socially very gregarious } \\
\text { easy-going } \\
\text { very fun to be around } \\
\text { she just gets me, we just get each } \\
\text { other }\end{array}$ \\
\hline & quite different from me & $\begin{array}{l}\text { we share the same life-style } \\
\text { initially }\end{array}$ \\
\hline & went to school with [name] & $\begin{array}{l}\text { supports the same football team as } \\
\text { me }\end{array}$ \\
\hline & another male, friend from work & $\begin{array}{l}\text { he can say the just absolutely } \\
\text { perfect thing }\end{array}$ \\
\hline & Engineer & $\begin{array}{l}\text { if you need her you can call her and } \\
\text { she is there }\end{array}$ \\
\hline
\end{tabular}


Figure 1

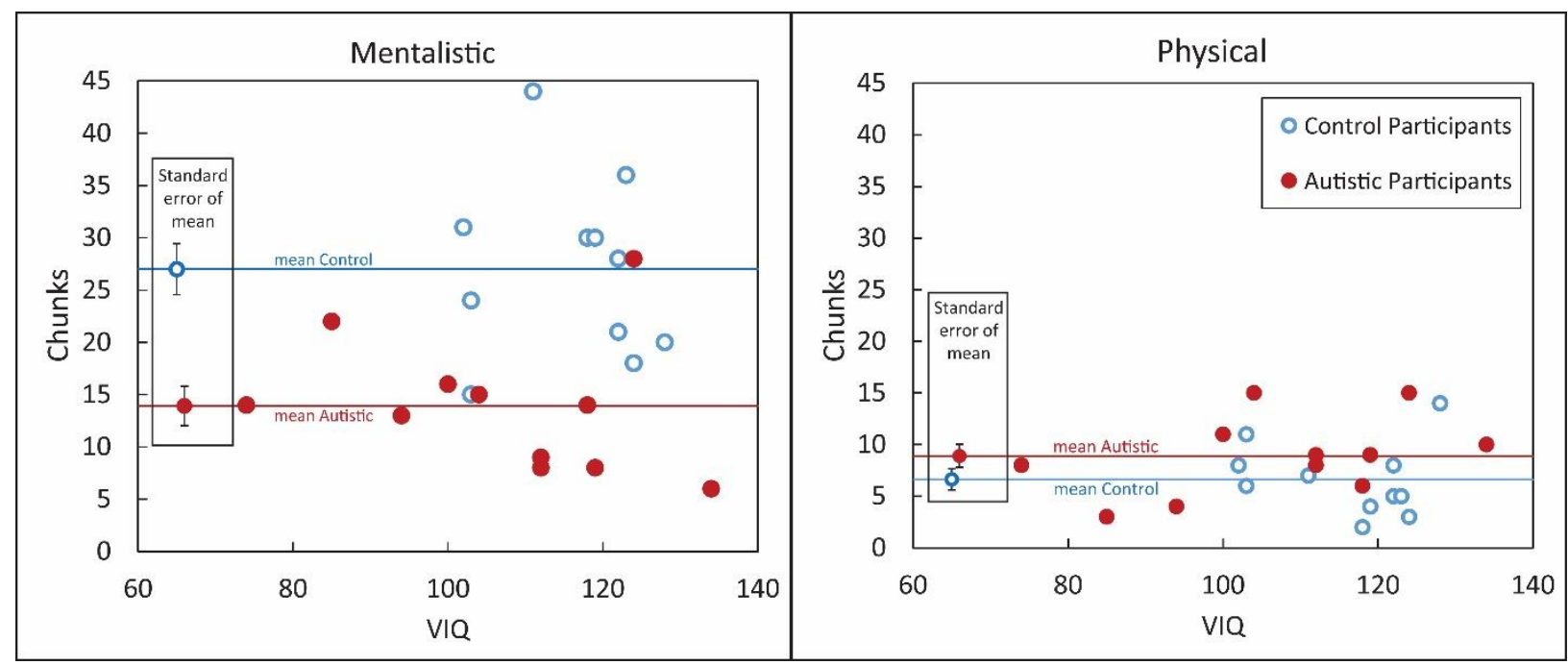

Figure 1. Number of mentalistic and physical chunks produced by participants. A significant difference between groups was observed in the production of mentalistic chunks but not in the production of physical chunks while differences in co-variate VIQ showed no effect. 